\title{
Comparative study and analyzes the power factor variation due to loading effect
}

\author{
Jyoti Lalotra ${ }^{1}$, Abhinav Sharma ${ }^{2}$ \\ M.Tech, EEE, Arni University, kathgarh, Himachal Pradesh, India ${ }^{1}$ \\ M.Tech, Electrical and Electronics Engineering, Arni University, Kathgarh (H.P), India ${ }^{2}$
}

\begin{abstract}
Power factor is most important for all industrial as well as domestic sectors. In this research paper present the comparative study and analyzes the power factor variation due to loading effect. For this comparison we take different values of inductance, three different range of capacitor and two range of resistance and their total impedance is calculated. The calculated theoretical and practical values of power factor on the basis of different combination loads. Pure sinusoidal sine waves are displayed in computer through sound card and calculate the load phase angle between the fundamental components of the load voltage and current.
\end{abstract}

Keywords: Microcontroller, power system, signal processing technique, power factor, resistance, inductance, capacitance.

\section{INTRODUCTION}

The power factor of an AC power system is expressed as the ratio of the actual power to the apparent power, where as the apparent is greater than the actual power. The apparent is the product of load voltage and current. PF is also defined as the cosine of the angle of lag or lead and also defined as the ratio of resistance to the impedance. In an electric power system, a low power factor can be the result of either a significant phase difference between the load voltage and load current. There are three parameters play the important role on power factor such as resistance $(\mathrm{R})$, capacitance $(\mathrm{C})$, inductance $(\mathrm{L})$. In pure resistive load, there is no phase difference between voltage and current. In pure inductive load, the current is lagging behind the voltage but practically it is not possible. In pure capacitive load, the current is leading behind the voltage but practically pure capacitive load is also not possible [1-11]. In RC series circuit is connected to the supply voltage. The impedance $(\mathrm{Z})$ and phase angle of $\mathrm{RC}$ series circuit is calculated as shown in equation (1) and (2).

$Z=\sqrt{R^{2}+X_{C}^{2}}$

To calculate the reactance for the capacitor

$X_{C}=\frac{1}{2 \pi f C}$

$\phi=\tan ^{-1}\left(\frac{X_{C}}{R}\right)$

In RLC series circuit are connected to the supply voltage. The impedance $(Z)$ and phase angle of RLC series circuit is calculated as shown in equation (3) and (4).

$Z=\sqrt{R^{2}+\left(X_{L}-X_{C}\right)^{2}}$

To calculate the reactance's for the inductor and the capacitor [12]

$X_{L}=2 \pi f L$

$X_{C}=\frac{1}{2 \pi f C}$

Copyright to IJARCCE $\phi=\tan ^{-1}\left(\frac{X_{L}-X_{C}}{R}\right)$

\section{Methodology}

In this research work we are analyzed the power factor variation due to loading effect. Now, we are taking the different blocks; First block is AC power stabilization with sensing circuit (i.e voltage and current), second block is different combination of load section, third block is step down voltage transformer (PT) and current transformer (CT) and the fourth block is sound card with signal processing unit. In the first block, the AC input voltage is applied to power stabilization with sensing circuit. In this block, the AC input voltage drop due to the fluctuations are stabilized by the PIC based microcontroller with other driver circuits. The output from the AC power stabilization with sensing circuit block is applied to the load which consists of series combinations of RC (resistor-capacitor) and RLC (resistor-inductor-capacitor). We have taken three different values of capacitance, two different values of resistance and varying inductance. The output from the load section is applied to the step down voltage transformer. PT and CT are used for measurement of the load voltage and current. Sinusoidal sine waves are displayed in computer through sound card and calculate the load phase angle between load voltage and current. The estimation of the power factor was taken by recording the voltage and current waveforms at $16,000 \mathrm{sa} / \mathrm{s}$ at 16-bit quantization and processing using digital signal processing algorithms.

In Table I, three observations are taken by changing the values of capacitor $(2.5 \mu \mathrm{F}, 15 \mu \mathrm{F}$ and $50 \mu \mathrm{F})$ and the value

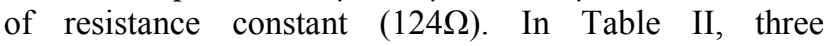
observations are taken by changing the values of inductor $(269.1 \mathrm{mH}, 590.6 \mathrm{mH}$ and $1232.0 \mathrm{mH})$, changing the values of capacitor $(2.5 \mu \mathrm{F}, 15 \mu \mathrm{F}$ and $50 \mu \mathrm{F})$ and keeping the

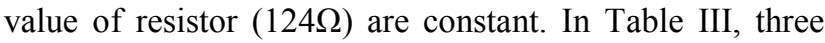
observations are taken by changing the values of inductor (363.0mH, $590.6 \mathrm{mH}$ and $1232.0 \mathrm{mH})$, keeping the value of 
resistor $(36 \Omega)$ and capacitor $(2.5 \mu \mathrm{F})$ are constant. In Table $\mathrm{IV}$, three observations are taken by changing the values of inductor $(873.0 \mathrm{mH}, 1073.0 \mathrm{mH}$ and $1232.0 \mathrm{mH})$, keeping the value of resistor $(36 \Omega)$ and capacitor $(15 \mu \mathrm{F})$ are constant.

TABLE I. DIFFERENT COMBINATIONS OF LOAD $(\mathrm{R}, \mathrm{C})$

\begin{tabular}{|c|c|c|}
\hline S. No. & $\mathbf{R}(\boldsymbol{\Omega})$ & $\mathbf{C}(\boldsymbol{\mu} \mathbf{F})$ \\
\hline 1 & 124 & 2.5 \\
\hline 2 & 124 & 15 \\
\hline 3 & 124 & 50 \\
\hline
\end{tabular}

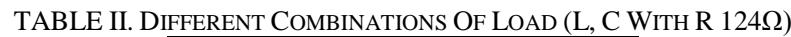

\begin{tabular}{|c|c|c|c|}
\hline S. No. & $\mathbf{R}(\boldsymbol{\Omega})$ & $\mathbf{L}(\mathbf{m H})$ & $\mathbf{C}(\boldsymbol{\mu} \mathbf{F})$ \\
\hline 1 & 124 & 269.1 & 50 \\
\hline 2 & 124 & 590.6 & 15 \\
\hline 3 & 124 & 1232.0 & 2.5 \\
\hline
\end{tabular}

TABLE III. DIFFERENT COMBINATIONS OF LOAD (L, C WITH R 36 $\Omega$ )

\begin{tabular}{|c|c|c|c|}
\hline S. No. & $\mathbf{R}(\boldsymbol{\Omega})$ & $\mathbf{L}(\mathbf{m H})$ & $\mathbf{C}(\boldsymbol{\mu} \mathbf{F})$ \\
\hline 1 & 36 & 363.0 & 2.5 \\
\hline 2 & 36 & 590.6 & 2.5 \\
\hline 3 & 36 & 1232.0 & 2.5 \\
\hline
\end{tabular}

TABLE IV. DIFFERENT COMBINATIONS OF LOAD (VARYING INDUCTOR With CONSTANT RESISTANCE $36 \Omega$ AND CAPACITOR $15 \mu \mathrm{F}$ )

\begin{tabular}{|c|c|c|c|}
\hline S. No. & $\mathbf{R}(\boldsymbol{\Omega})$ & $\mathbf{L}(\mathbf{m H})$ & $\mathbf{C}(\boldsymbol{\mu} \mathbf{F})$ \\
\hline 1 & 36 & 873.0 & 15 \\
\hline 2 & 36 & 1073.0 & 15 \\
\hline 3 & 36 & 1232.0 & 15 \\
\hline
\end{tabular}

\section{III.RESULT AND DISCUSSION}

Experimental results are obtained from the comparison of different combination of loads (RC and RLC) on the microcontroller based power system. Investigations of the change in the power factor due to loading effect has been evaluated and analyzed. Calculations of the power factor are carried out using signal system and processing unit. Fig. 1(a-c) represents the segmented output voltage and current waveforms for three different combinations of the load (constant resistor $124 \Omega$ and varying capacitor) with duration of $0.3 \mathrm{~s}$. Fig. 2(a-c) represents the segmented output voltage and current waveforms for three different combinations of the load (constant resistor $124 \Omega$, varying inductor and capacitor) with duration of 0.3s. Fig. 3(a-c) represents the segmented output voltage and current waveforms for three different combinations of the load (varying inductor, keeping resistor $36 \Omega$ and capacitor $2.5 \mu \mathrm{F}$ are constant) with duration of $0.3 \mathrm{~s}$. Fig. 4(a-c) represents the segmented output voltage and current waveforms for three different combinations of the load (varying inductor, keeping resistor $36 \Omega$ and capacitor $15 \mu \mathrm{F}$ are constant) with duration of $0.3 \mathrm{~s}$ and their total impedance is calculated with all the values of the capacitor, inductor and resistor. Theoretical values of the power factor were calculated. From the output waveforms of current and voltage the practical value of the power factor were obtained. Both theoretical and practical calculated values of power factor are shown in Table V,
Table VI, Table VII, and Table VIII. In Table V, the minimum value of theoretical power factor is 0.097 and corresponding practical power factor is 0.104. The maximum value of theoretical power factor is 0.89 and corresponding practical power factor is 0.89 . In Table VI, the minimum value of theoretical power factor is 0.1384 and corresponding practical power factor is 0.1478 . The maximum value of theoretical power factor is 0.986 and corresponding practical power factor is 0.987 .

TABLE V. CALCULATION OF IMPEDANCE, THEORETICAL AND PRACTICAL VALUE OF PF FOR LOAD (CONSTANT RESISTANCE AND VARYING CAPACITOR)

\begin{tabular}{|c|c|c|c|c|}
\hline S. No. & $\begin{array}{c}\text { Impedance } \\
\mathbf{Z}(\boldsymbol{\Omega})\end{array}$ & $\begin{array}{c}\text { P.F. } \\
\text { Theoretical }\end{array}$ & $\begin{array}{c}\text { P.F. } \\
\text { Practical }\end{array}$ & Error \\
\hline 1 & 1279.3 & 0.097 & 0.104 & 0.932 \\
\hline 2 & 245.8 & 0.504 & 0.515 & 0.978 \\
\hline 3 & 139.4 & 0.89 & 0.89 & 1.000 \\
\hline
\end{tabular}

TABLE VI. CALCULATION OF IMPEDANCE, THEORETICAL AND PRACTICAL VALUE OF PF WITH ERROR FOR LOAD (VARYING INDUCTOR

\begin{tabular}{|c|c|c|c|c|}
\hline \multicolumn{5}{|c|}{ AND CAPACITOR WTIH CONSTANT RESISTANCE $124 \Omega)$} \\
\hline S. No. & $\begin{array}{c}\text { Impedance } \\
\mathbf{Z ( \Omega )}\end{array}$ & $\begin{array}{c}\text { P.F. } \\
\text { Theoretical }\end{array}$ & $\begin{array}{c}\text { P.F. } \\
\text { Practical }\end{array}$ & Error \\
\hline 1 & 125.7 & 0.986 & 0.987 & 0.998 \\
\hline 2 & 126.8 & 0.977 & 0.997 & 0.979 \\
\hline 3 & 894.8 & 0.1384 & 0.1478 & 0.9364 \\
\hline
\end{tabular}

TABLE VII. CALCULATION OF IMPEDANCE, THEORETICAL AND PRACTICAL VALUE OF PF WITH ERROR FOR LOAD (VARYING INDUCTOR WITH CONSTANT CAPACITOR $2.5 \mu \mathrm{F}$ AND RESISTANCE $36 \Omega$ )

\begin{tabular}{|c|c|c|c|c|}
\hline S. No. & $\begin{array}{c}\text { Impedance } \\
\mathbf{Z}(\boldsymbol{\Omega})\end{array}$ & $\begin{array}{c}\text { P.F. } \\
\text { Theoretical }\end{array}$ & $\begin{array}{c}\text { P.F. } \\
\text { Practical }\end{array}$ & Error \\
\hline 1 & 1159.76 & 0.0310 & 0.0317 & 0.977 \\
\hline 2 & 1088.29 & 0.0330 & 0.0334 & 0.988 \\
\hline 3 & 886.93 & 0.0405 & 0.0410 & 0.987 \\
\hline
\end{tabular}

TABLE VIII. CALCULATION OF IMPEDANCE, THEORETICAL AND PRACTICAL VALUE OF PF WITH ERROR FOR LOAD (VARYING INDUCTOR WITH CONSTANT RESISTANCE $36 \Omega$ AND CAPACITOR $15 \mu \mathrm{F})$

\begin{tabular}{|c|c|c|c|c|}
\hline S. No. & $\begin{array}{c}\text { Impedance } \\
\mathbf{Z}(\boldsymbol{\Omega})\end{array}$ & $\begin{array}{c}\text { P.F. } \\
\text { Theoretical }\end{array}$ & $\begin{array}{c}\text { P.F. } \\
\text { Practical }\end{array}$ & Error \\
\hline 1 & 71.74 & 0.5033 & 0.5012 & 1.004 \\
\hline 2 & 129.97 & 0.2775 & 0.2769 & 1.002 \\
\hline 3 & 178.51 & 0.2020 & 0.2008 & 1.005 \\
\hline
\end{tabular}

In Table VII, the minimum value of theoretical power factor is 0.0310 and corresponding practical power factor is 0.0317 . The maximum value of theoretical power factor is 0.0405 and corresponding practical power factor is 0.0410. In Table VIII, the minimum value of theoretical power factor is 0.2020 and corresponding practical power factor is 0.2008 . The maximum value of theoretical power factor is 0.5033 and corresponding practical power factor is 0.5012 . Also the error calculated by dividing theoretical and practical calculated values is shown. The calculated theoretical and practical values of power factor are plotted in Fig. 5 to Fig. 8 with different impedance values. There is also some difference in theoretical and practical calculated values are seen in the plot for different 0.17148/IJARCCE 
combinations which may arise due to leakage of the inductive or capacitive components.

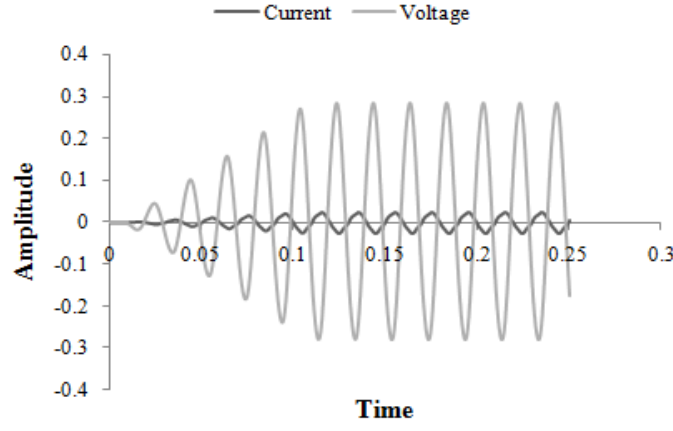

(a). $\mathrm{Z}=1279.3$

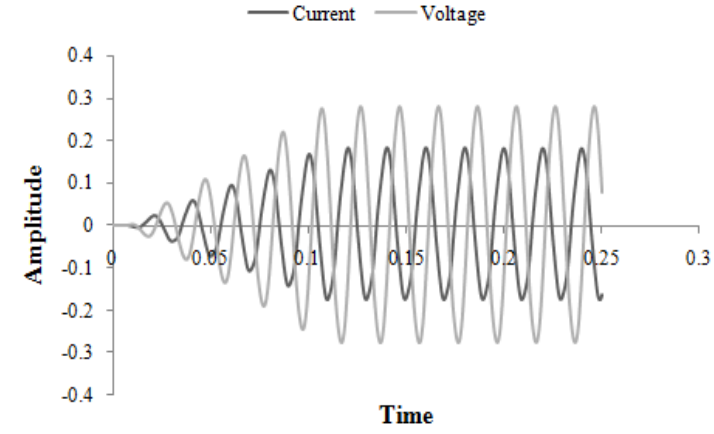

(b). $Z=245.8$

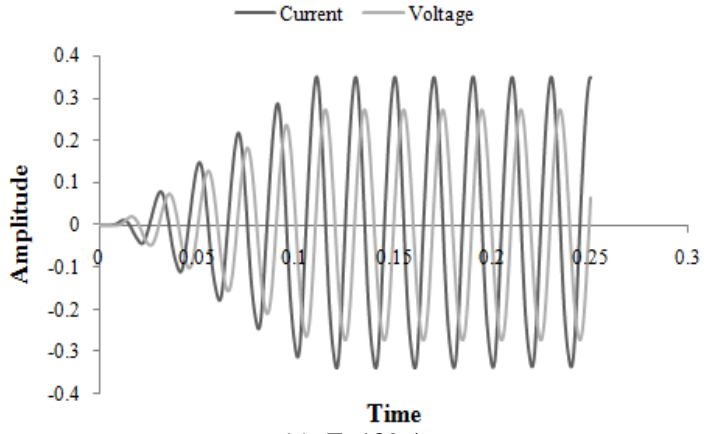

(c). $\mathrm{Z}=139.4$

Fig. 1(a-c) Waveform of output current and voltage are recorded at 16,000 sampling rate for three different values of capacitance and resistance constant

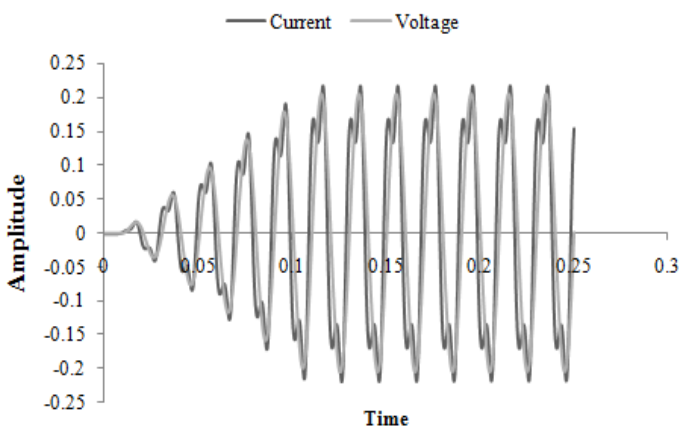

(a). $\mathrm{Z}=125.7$

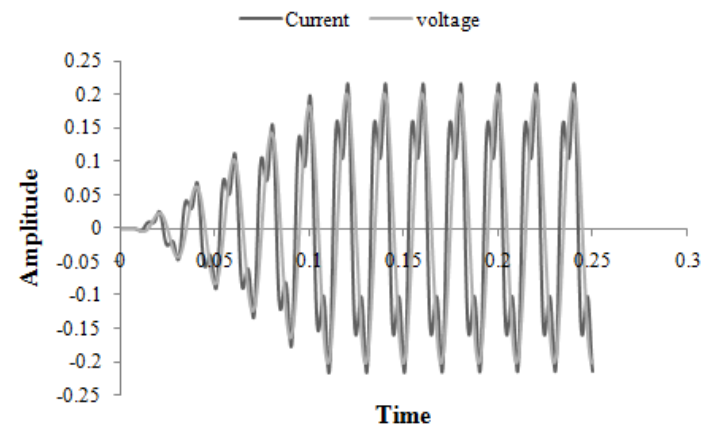

(b). $Z=126.8$

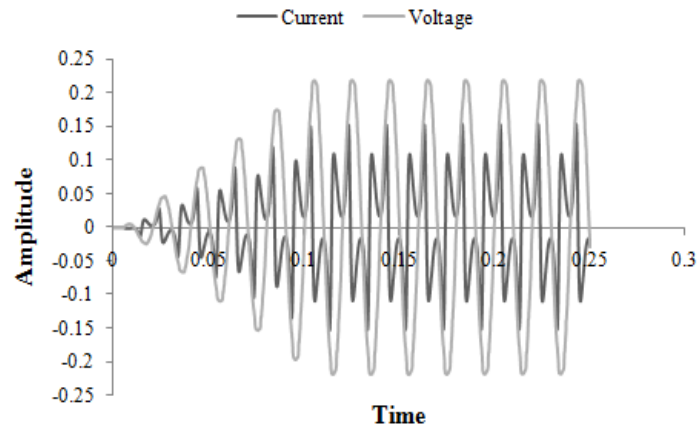

(c). $\mathrm{Z}=894.8$

Fig. 2(a-c) Waveform of output current and voltage are recorded at 16,000 sampling rate for three different values of inductance and capacitor keeping resistance $(124 \Omega)$ constant 


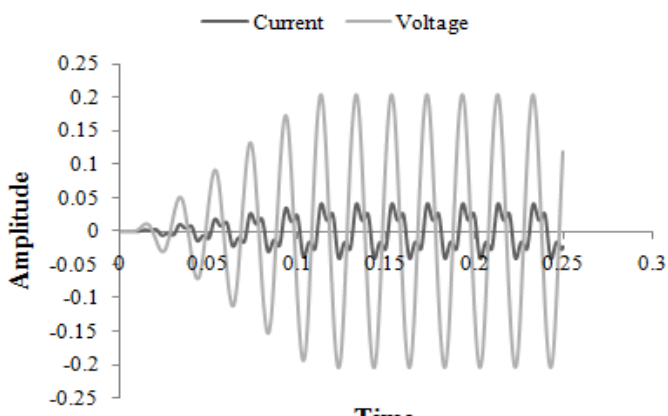

(a). $\mathrm{Z}=1159.76$

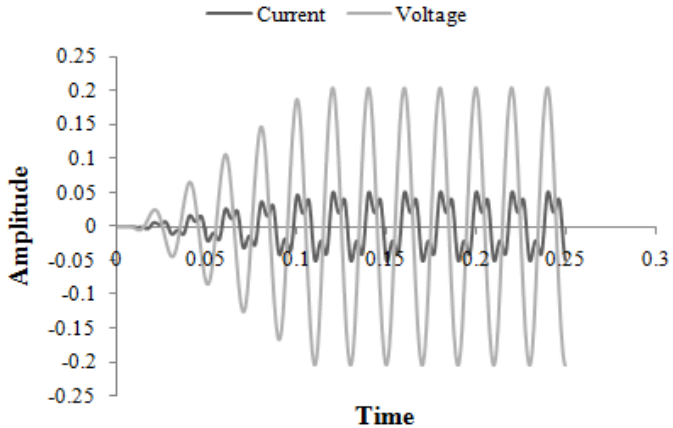

(b). $\mathrm{Z}=1088.29$

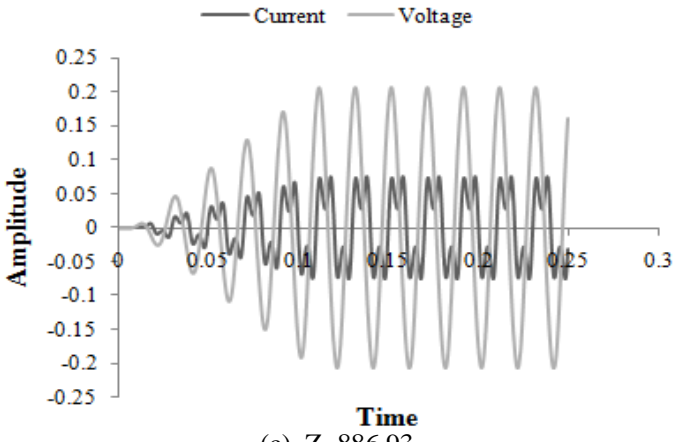

(c). $\mathrm{Z}=886.93$

Fig. 3(a-c) Waveform of output current and voltage are recorded at 16,000 sampling rate for three different values of inductance and keeping the value of capacitor $(2.5 \mu \mathrm{F})$, resistance $(36 \Omega)$ are constant

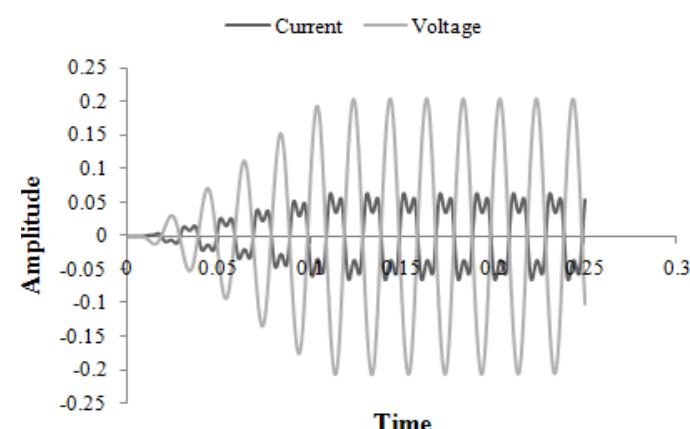

(a). $Z=71.74$

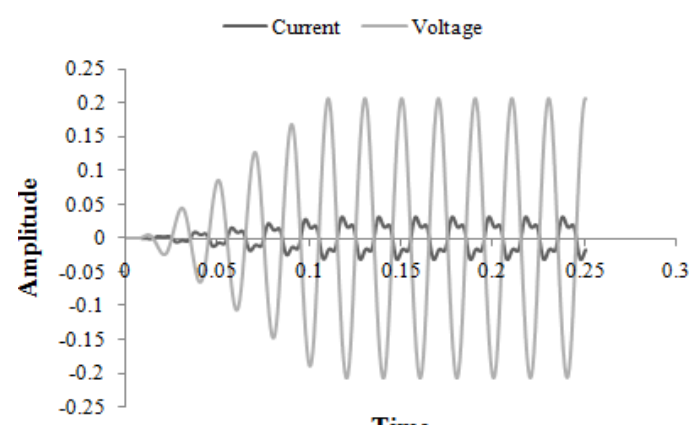

(b). $Z=129.97$

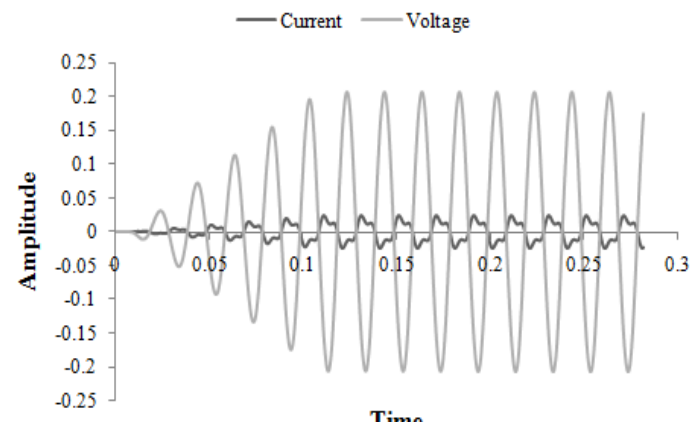

(c). $\mathrm{Z}=178.51$

Fig. 4(a-c) Waveform of output current and voltage are recorded at 16,000 sampling rate for three different values of inductance and keeping the value of capacitor $(15 \mu \mathrm{F})$, resistance $(36 \Omega)$ are constant 
- P.F.(Theoretically) $\quad$ P.F.(Practically)

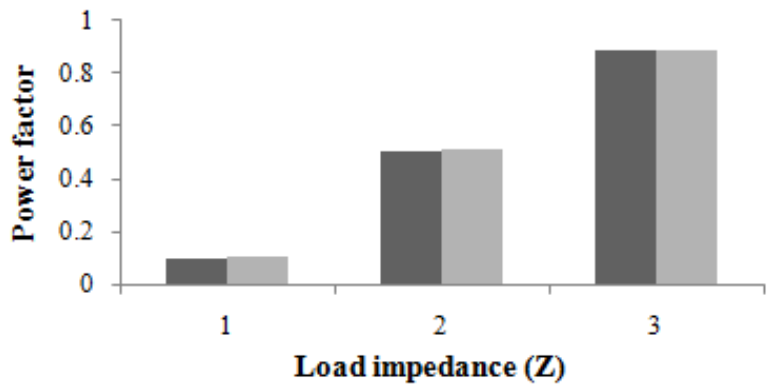

Fig. 5 Theoretical and practical calculated value of power factor for different combinations of impedance $(\mathrm{R}, \mathrm{C})$

-P.F.(Theoretically) $\quad$ P.F.(Practically)

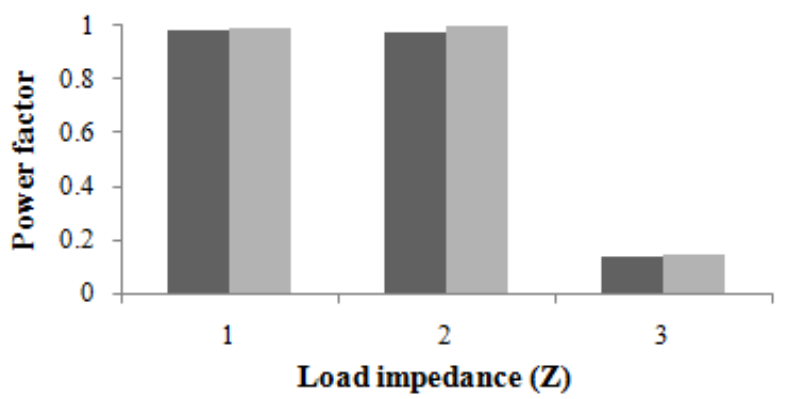

Fig. 6 Theoretical and practical calculated value of power factor for different combinations of impedance (varying inductor and capacitor with constant resistor $124 \Omega$ )

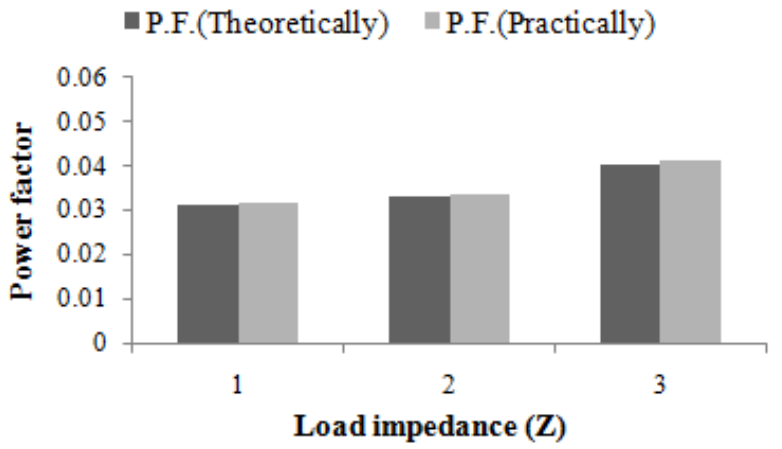

Fig. 7 Theoretical and practical calculated value of power factor for different combinations of impedance (varying inductor with constant resistor $36 \Omega$ and capacitor $2.5 \mu \mathrm{F}$ )

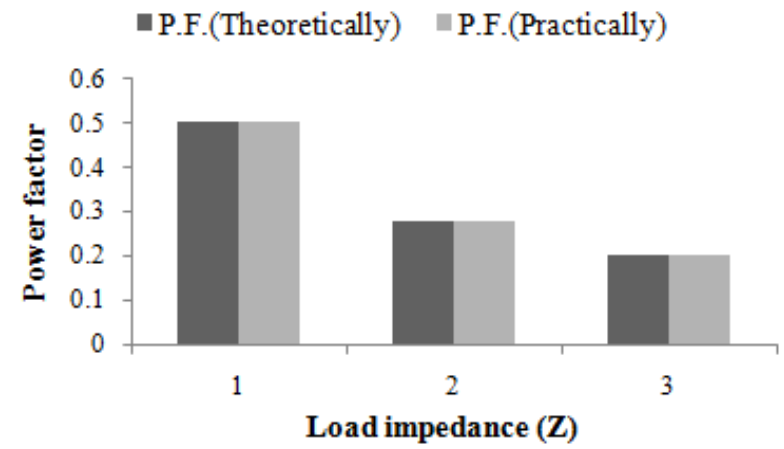

Fig. 8 Theoretical and practical calculated value of power factor for different combinations of impedance (varying inductor with constant resistor $36 \Omega$ and capacitor $15 \mu \mathrm{F}$ )

\section{IV.CONCLUSION}

In this paper present the comparative study and analyzed the power factor variation due to loading effect. Calculations of the power factor were carried out using digital signal processing algorithms. Different combinations of loads (RC and RLC) were investigated for affecting the performance of the system. The maximum value of theoretical power factor is 0.986 and the maximum value of practical power factor is 0.997 . The minimum value of theoretical power factor is 0.0310 and the minimum value of practical power factor is 0.0317 . The estimation of the power factor was taken by recording the voltage and current waveforms at 16,000sa/s at 16-bit quantization and processing using digital signal processing algorithms.

\section{REFERENCES}

[1] P. Sundaram et al., "Power factor management in marble industry," Int. J. of Sci., Eng. and Technol. Research (IJSETR), vol. 2, issue 3, 2013, pp. 585-590.

[2] M. Bapat, "Power factor improvement and energy conservation through use of intelligent power factor controller," Water and Energy Abstracts, Indian J., vol. 18, 2008.

[3] M.H. Shwedhi and M.R. Sultan, "Power factor correction capacitors; Essentials and cautions," Power Eng. Society Summer Meeting, IEEE, vol. 3, 16-20, 2000, pp. 1317-1322.

[4] H.Z. Azazi et al., "Review of passive and active circuits for power factor correction in single phase, Low power ACDC converters," Proc. of the 14th Int. Middle East Power Syst. Conf. (MEPCON'10), Cairo University, Egypt, 19-21, 2010, pp. 217-224.

[5] R. Natarajan, Power System Capacitors, Taylor \& Francis Group, CRC Press, 2005.

[6] Jain Sandesh et al., "Improve power factor and reduce the harmonics distortion of the system,” Res. J. Eng. Sci., vol. 1(5), 2012, pp. 31-36.

[7] M. Rashid, Power electronics handbook, Academic Press, 2001.

[8] P. Vijaya Prasuna et al, "Improvement in power factor \& THD using dual boost converter," Int. J. of Eng. Research and Applicat. (IJERA), vol. 2, issue 4, 2012, pp. 2368-2376.

[9] Abhinav Sharma et al., "Effect of impedance load on the power factor of microcontroller based power system," Int. J. of Eng. and Advanced Technol. (IJEAT), vol. 2, issue 5, June 2013, pp. 419-422.

[10] A. Sharma et al., "Dependence of power factor on inductive loads for microcontroller based power systems," IOSR J. of Elect. and Electron. Eng. (IOSR-JEEE), vol. 7, issue 2, 2013, pp. 30-35.

[11] A. Sharma et al., "Investigation of the effect of RLC load on power factor of microcontroller based power system," Int. J. of Innovative Research in Sci., Eng. and Technol .(IJIRSET), vol. 2, issue 8, 2013, pp. 3664-3670.

[12] T. R. Kuphaldt, Lessons In Electric Circuits, Sixth Edition, vol. 2, last update July 25, 2007.

\section{BIOGRAPHIES}

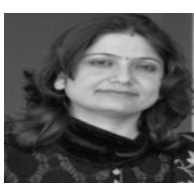

Er. Jyoti Lalotra received her M.Tech. Degree in EEE from Arni University, kathgarh, Himachal Pradesh, India and Bachelor degree in Electrical Engineering from M.B.S.C.E.T, affiliated to University of Jammu (J\&K) and also received the Master of Business Administration from Lovely Professional University Jalandhar (Punjab), India. She received her Advance Diploma in industrial Automation \& System Design from C-DAC, Mohali, Punjab and also received Advance Certificate in Power Distribution Management from Indira Gandhi National Open University, New Delhi, India. She has attended the two day workshop electronic system design and manufacturing (ESDM) organised by IETE and CART Bharat, Jammu. She is presently working as DOI $10.17148 /$ IJARCCE 
lecturer in Department of Electrical Engineering, IECS polytechnic college, Jammu.

Er. Abhinav Sharma received his M.Tech. Degree in Electrical and Electronics Engineering from Arni University, Kathgarh (H.P), India and B.E. Degree in Electrical Engineering from Mahant Bachitttar Singh College of Engineering and Technology, University of Jammu, India. He received his Advance Diploma in Industrial Automation \& System Design from C-DAC, Mohali, Punjab and also received Advance Certificate in Power Distribution Management from Indira Gandhi National Open University, New Delhi, India. 